\title{
Labirintos identitários na escrita e nos desenhos de Else Lasker-Schüler ${ }^{1}$
}

\section{Manuela Veloso}

ISCAP - ILCML

Resumo: De nacionalidades e géneros diversos, as estratégias discursivas das pessoas poéticas que Else Lasker-Schüler adopta nos seus textos e desenhos apontam para novos rumos perceptivos. Analisarei alguns exemplos desses itinerários identitários na sua obra. A auto-figuração pictórica e literária Prinz Jussuf von Theben [Princípe Jussuf de Tebas] - é uma personagem encenada e ilustrada ao longo de vários contos, cartas e postais. Um outro alter-ego de Lasker-Schüler é a princesa Tino, protagonista no sonho relatado em vários contos, Die Nächte der Tino von Bagdad [As noites de Tino de Bagdad] (1907), de novo, reportando ao orientalismo sempre presente na obra de Else Lasker-Schüler. A articulação do texto e da imagem volta a verificar-se em Briefen nach Norwegen [Cartas para a Noruega], publicadas em Der Sturm entre 1911 e 1912 por Lasker-Schüler, mais tarde publicadas sob o título Mein Herz - Ein Liebesroman mit Bildern und wirklich lebenden Menschen [O Meu Coração - Um Romance de Amor com quadros e pessoas realmente vivas]. Os contos ortónimos de 1910, de que são exemplo Tigerin, Affe und Kuckuck [A Tigreza, o Macaco e o Cuco], Im Neopathetischen Kabarett [No Cabaré Neopatético], permitem constatar como a autora exercia a abstracção na escrita pela via de outro entendimento de "forma", premissa que continuará a ser verificável na sua poesia da fase dos primeiros anos da revista Der Sturm (1909-12), designadamente em “Versöhnung” ["Reconciliação"] e em "Ein alter Tibetteppich" [“Um Velho Tapete do Tibete”]. É na poesia que Lasker-Schüler radicaliza em metáfora a comunicação intra e inter-corpórea.

Palavras-chave: itinerários identitários, auto-figurações literárias e pictóricas, Oriente e Ocidente, 
abstraccionismo literário, comunicação intra e inter-corpórea

Abstract: From diferent nationalities and genders, the discourse strategies adopted by Else Lasker-Schüler's ficcional personae both in writing and drawing point out to new perceptive routes. Some of these identitary itineraries will be hereby analysed. The literary and sketched self-firuration Prinz Jussuf von Theben [Prince Jussuf from Thebes] is a dramatized and illustrated character throughout several short stories, letters and postcards. Another Lasker-Schüler's alter-ego is the princess Tino - main character of the dream told over the tales of Die Nächte der Tino von Bagdad [The Nights of Tino from Bagdad] (1907), and again alluding to the omnipresent orientalism in Else Lasker-Schüler's work. The articulation between Text and Image reappears in Briefen nach Norwegen [Letters to Norway], brought out in Der Sturm between 1911 and 1912, and later published in a book entitled Mein Herz - Ein Liebesroman mit Bildern und wirklich lebenden Menschen [My Heart. Novel with drawings] (1912). Her short stories from 1910 - like Tigerin, Affe und Kuckuck [Tigress, Monkey and Cuckoo], Im Neopathetischen Kabarett [At Neopathetic Cabaret] - concur to realize how LaskerSchüler delivered abstraction in literature by means of a peculiar conception of "form". This premise is also verifiable in her poetry of the early years of the little magazine Der Sturm (1909-12), namely in "Versöhnung" ["Atonement"] and "Ein alter Tibetteppich" ["An Old Tibetan Carpet"]. It is, actually, in poetry that LaskerSchüler radically transmutes metaphor into a sort of intra- and inter-body communication.

Keywords: identitary itineraries, literary and drawing self-figurations, West and East, literary abstractionism, intra- and inter-body communication 


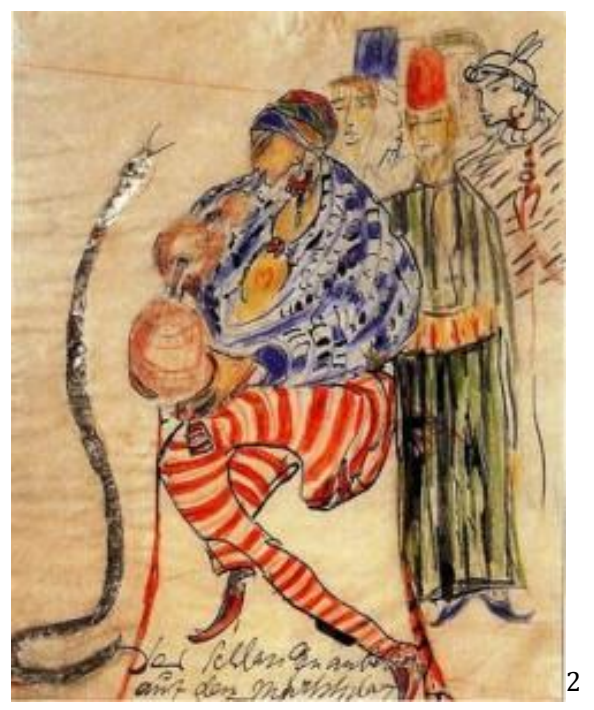

Die Schlang welche sich nicht häuten kann geht zu Grunde. Ebenso die Geister welche man verhindert ihre Meinungen zu wechseln - sie hören auf Geist zu sein. (Nietzsche, Morgenröte) [A cobra que não consegue mudar de pele perece. Da mesma forma, os espíritos a quem se impede que mudem de opinião - cessam de ser espírito.]

A arte vanguardista, de que o Expressionismo Alemão é um parente de peso, surge com o intuito de inquietar uma qualquer ordem estabelecida e de deixar nela um rastro, o que nos leva a admitir como verdadeira a premissa de Marshall Macluhan quando usava a metáfora do espelho retrovisor - que não mostra o que passou mas antevê o que está para vir (cf. MacLuhan 1977). Em A Intervenção Surrealista (1966)³, Mário Cesariny dizia: "Procuramos, procuro, uma experiência que não seja maior do que o experimentador". Essa 
busca só é comensurável a dois tempos: o do ímpeto inevitável de interromper o circunstancial e o da sua persistência na reconfiguração do fluxo da vida ou vidas. Vejamos, brevemente, como se procurou labirinticamente a autora aqui visitada no quadro da vanguarda alemã.

\author{
Weltflucht \\ Ich will in das Grenzenlose \\ Zu mir zurück, \\ Schon blüht die Herbstzeitlose \\ Meiner Seele, \\ Vielleicht ists schon zu spät zurück. \\ 0 , ich sterbe unter euch! \\ Da ihr mich erstickt mit euch. \\ Fäden möchte ich um mich ziehen \\ Wirrwarr endend! \\ Beirrend, \\ Euch verwirrend, \\ Zu entfliehn \\ Meinwärts.
}

\section{Fuga ao Mundo}

Quero chegar ao sem limite

Para regressar a mim

Já estão em flor os narcisos-do-outono...

Tarde demais, quem sabe... regressar

Ah, morro no meio de vós

Os que convosco me sufocais.

Queria tecer uma teia de fios a envolver-me

Pôr fim à confusão,

Confundindo,

E fugir

Para dentro de mim. ${ }^{4}$

Apesar de ser um dos poemas menos conhecidos de Else Lasker-Schüler, este é um poema que indicia marcas de Expressionismo, ainda que os contrastes e distorção sejam mais ténues do que os da pintura masculina de alguns amigos da fase que antecedeu a Primeira Guerra (cf. Barrento 2002: 13). É um poema que reclama a eliminação de limites, sejam eles territoriais, religiosos ou ideológicos. Em 1911, Lasker-Schüler tinha-se tornado numa das mais notáveis figuras ligadas à escrita. Nesta altura ela era já autora de três volumes de poesia, um livro de ensaio e ilustrações à memória do escritor anarquista Peter Hille e uma peça de teatro, Die Wupper. Gabriele Münter referia-se às frequentes imitações do estilo de Lasker-Schüler como "herum zu laskern" ["à moda de Lasker"] (apud Bauschinger 1980: 85).

Os anos que antecederam a Primeira Grande Guerra têm a maior relevância para uma avaliação da situação das mulheres ligadas à literatura e às artes em geral. A predominância de escritores e artistas masculinos é ainda uma evidência. Nas artes plásticas do Expressionismo ainda constatamos a presença de mulheres - como Marianne 
von Werefkin, Gabriele Münter, Nell Walden - na literatura, Else Lasker-Schüler é a única mulher com real notoriedade.

Em 1918, Kasimir Edschmid classifica Lasker-Schüler como uma figura de proa entre os grandes poetas da época, por ser mais intemporal do que os outros e por isso permanece um epifenómeno capaz de levar o leitor a sentir a quintessência da poesia: "Sie ist eine der größten Dichterinnen, weil sie zeitloser ist als alle, sie tritt dich neben das Hohe Lied (...) Die Lasker hat nichts um sich" ["Ela é uma das maiores poetas de sempre, porque ao contrário dos outros, é intemporal, e leva-nos à quintessência da poesia ... A Lasker não tem ninguém similar "] (Anz/Stark, Hg., 1982: 53).

$\mathrm{Na}$ antologia de textos expressionistas de 1922, Menschheitsdämmerung [Aurora da Humanidade], Kurt Pinthus publica vários poemas de Else Lasker-Schüler e afirma que ela é uma das poucas figuras literárias que se distinguem da multidão. Em 1925 Carl Zuckmayer refere-se aos mais notáveis intelectuais de Berlim e elenca figuras como Albert Einstein, Else Lasker-Schüler, Bertolt Brecht, etc. (Miller 1999: 135). Mas já em Junho de 1912, no seu artigo "Gegen die Neutöner" ["Contra os Novos Tons”], Karl Kraus havia dito, na revista que editava, Die Fackel: "Ich halte Else Lasker-Schüler für eine große Dichterin. Ich halte alles, was um sie herum neugetönt wird, für eine Frechheit" ["Considero a Else LaskerSchüler uma grande poeta. Considero todo o resto que se produz ao pé dela um atrevimento"] (Anz / Stark, Hg. 1982: 86).

Jean Michel Palmier chama a ELS, como era conhecida pelos amigos, "'La clocharde céleste'5, e diz: 'elle traversa le ciel expressioniste à la manière d'une étrange météore. Il est vrai qu'elle passe d'une idée à l'autre avec une rapidité incroyable et qu'elle illumine tout ce qu'elle renconte'. A sua escrita move-se à velocidade da luz, sempre que quer impactar sensações. O poema "Mein blaues Klavier" ["O meu Piano Azul”], do seu último livro de poesia (1932-1945) - com o mesmo nome, é disso emblemático. 0 abstraccionismo literário confere ao lastro do texto o inexcedível poder da projecção artística e espiritual: "Ich habe zu Hause ein blaues Klavier / Und kenne doch keine Note (...) [“Tenho em casa um piano azul / E não toco uma única nota”], (...) “Es spielen Sternenhände vier" [“É tocado a quatro 
mãos estrelares"], (...) / "Zerbrochen ist die Klavitür...../ Ich beweine die blaue Tote" [“0 teclado está partido..... / Eu choro aquela coisa azul morta"].

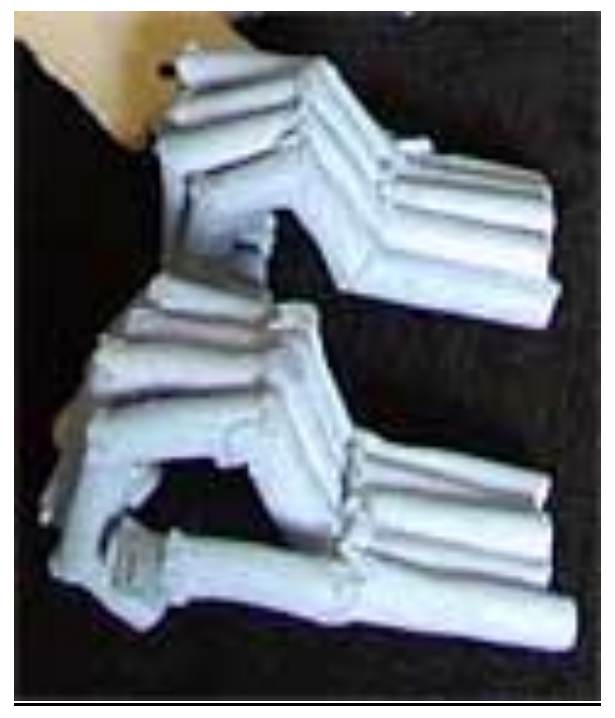

Detalhe de Hände zum blauen Klavier" ["Mãos para piano azul“] recente instalação de cerâmica Jürgen Christoph Buschbeck

Lasker-Schüler (1869-1945) percorreu trajectórias múltiplas tanto na realidade como na arte. Nasce em Wuppertal Elberfeld, na região do Ruhr e morre na Palestina. De origem judaica, vive em Berlim de 1894 a 1933, ano do seu exílio em Zurique; em 1932 tinha recebido o prémio Kleist. A partir de 1939, vive em Jerusalém, onde morre aos 61 anos, muito ilustre nos círculos artísticos desta cidade. Em Berlim, a polémica e a consagração, a solidão e a imensa entourage de figuras artísticas, ilustres e desconhecidas, tinham feito parte da sua vida.

Em 1920, Paul Cassier publica as Briefe und Bilder [Cartas e Quadros], uma troca literária de correspondência, em que a alterogenia surge como uma via de a linguagem teórica consolidar uma simbólica sobre as relações entre perceber, intuir e descrever, entre imagem e palavra, numa dimensão em que o jogo do alter-ego é como um código de honra de um micro-sistema expressionista: Else Lasker-Schüler é Prinz Jussuf von Theben [o Príncipe Jussuf de Tebas], Franz Marc é Der blaue Reiter [O Cavaleiro Azul], Franz Werfel é 
Der Prinz von Prag [O Príncipe de Praga], Georg Trakl Der Ritter aus Gold [O Cavaleiro de Ouro], Oskar Kokoschka é Der Troubador oder der Riese [O Trovador ou o Gigante], Tilla Durieux é Die Schwarze Leopardin [A Leoparda Negra] e Herwarth Walden é consagrdo Im Königreich Theben Georg Levin [Georg Levin no Reino de Tebas].

A partir de 1911, começou a publicar textos com ilustrações próprias e em 1916 os seus desenhos - a lápis, pena e óleo - já eram expostos no Hagener Folkwang-Museum. Seguiram-se, enquanto viva, outras exposições, em Berlim e Londres. Em 2001, comissariada por Ricarda Dick, foi levada a cabo a exposição sobre a obra de Else LaskerSchüler - 'Schrift: Bild: Schrift' ['Escrita: Imagem: Escrita'] na Casa August Macke, em Bona' ${ }^{6}$

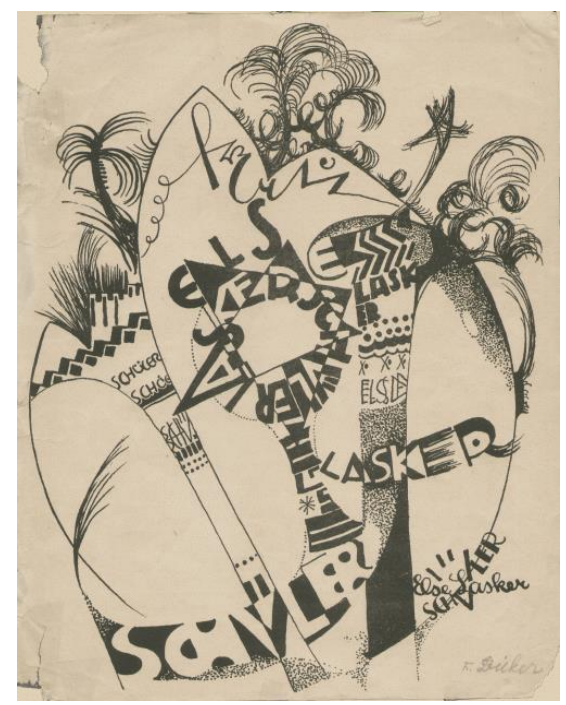

Cartaz do Recital de poesia de E. Lasker-Schüler na Bauhaus, em 1920, com ilustração da autora

Karl Kraus chamou a Else Lasker-Schüler Der schwarze Schwan Israels [O Cisne Negro de Israel] e ela própria diz, em «Mein Stilles Lied» ["Minha canção quieta"], "Ich bin der Hieroglyph, / Der unter der Schöpfung steht" ["Sou o hieróglifo inscrito sob a obra da criação"] (Barrento 1989: 10). Lasker-Schüler é uma criatura de sonhos. As alter-personae que ela cria e vão percorrendo a sua aparição ficcional, são veículo de alternância nos géneros, meios de expressão, espaços e tempos, sendo que a linha que separa o fantástico do utópico é muito ténue. 


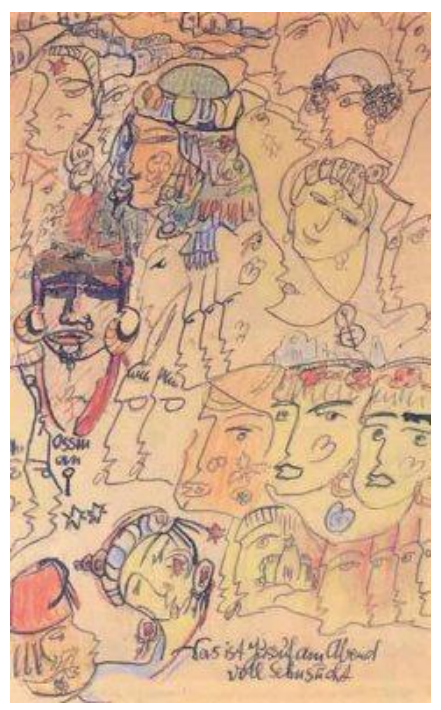

Else Lasker-Schüler: Zeichnung [Desenho]

Os desenhos de Lasker-Schüler fazem emergir os seus grandes temas políticos: o jogo com o papel dos géneros, a consternação perante a guerra e o poder e a enérgica defesa da igualdade de direitos das mulheres. A procura rebelde de quem é continua até ao fim da sua vida, como se pode constatar na peça, escrita no exílio em Jerusalém, IchundIch [EueEu] (1937-41), em que traça o seu perfil em duas facetas justapostas. 0 rendez-vous consigo própria decorre nesta peça numa atmosfera faustiana de dualidade e antagonismo. A ilusão da unicidade entre os seres é superada pela decisão de habitar cosmicamente a existência. 0 poema «Abschied» é muito ilustrativo deste tipo de sensação de separação e estranhamento veiculado pelos autores do Modernismo, mas projectado de uma forma singular por Else Lasker-Schüler:

Abschied

Aber du kamst nie mit dem Abend Ich saß im Sternenmantel.

...Wenn es an mein Haus pochte, War es mein eigenes Herz.

Das hängt nun an jedem Türpfosten, Auch an deiner Tür;

\section{[Despedida}

Mas tu nunca vinhas com a noite E eu sentada com casaco de estrelas.

... Quando batiam à minha porta era o meu próprio coração.

Agora pendurado em todas as ombreiras, Também na tua porta; 
Zwischen Farren verlöschende Feuerrose Im Braun der Guirlande.

Ich färbte dir den Himmel brombeer Mit meinem Herzblut.

Aber du kamst nie mit dem Abend ...Ich stand in goldenen Schuhen.
Entre touros rosa-de-fogo a extinguir-se No castanho da grinalda.

Tingi-te o céu de groselha

Com o sangue do meu coração.

Mas tu nunca vinhas com a noite -

... E eu de pé com sapatos dourados. $]^{7}$

Dada a sua visão fraccionada da realidade exterior, demarcada por fronteiras inorgânicas, Else Lasker-Schüler recorre, reiteradamente, ao cruzamento do Ocidente e do Oriente nos seus textos e ilustrações, bem como à invenção de mundos e identidades várias, femininas ou masculinas: Jussuf - príncipe de Tebas, Abigail, Tino - princesa de Bagdad, ou Robinson, o índio Jaguar Azul. o desocultamento de novos ideais constitui um grande desafio civilizacional - "an ever expanding sea of massive data", 8 usando uma expressão de Noam Chomsky numa entrevista publicada com o título "Noam Chomsky on Where Artificial Intelligence Went Wrong". Ao falarmos de ELS, sentimo-nos muito acompanhados neste tipo de indagações. A "inteligência artificial” era de outra índole na época em que esta autora se expressou. No entanto, o eco das suas perplexidades faz-se sentir nos tempos que correm. Diariamente a página da ELS Gesellschaft ${ }^{9}$ dá informação sobre as diversas efemérides que estão na ordem do dia, a propósito do legado da autora.

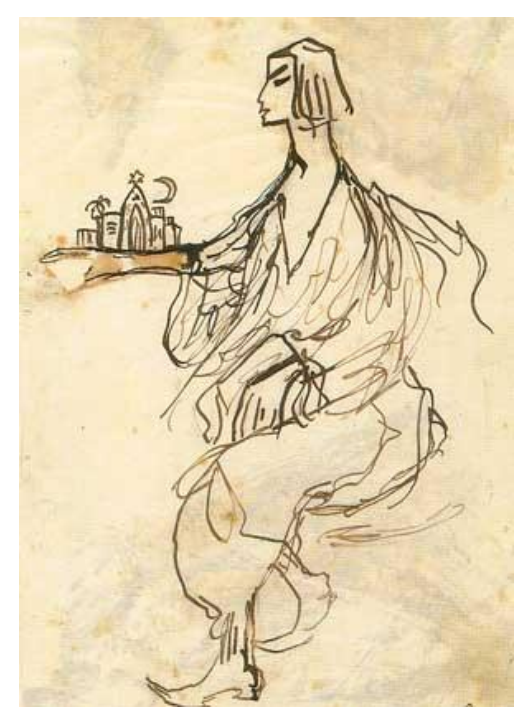

Auto-Retrato de Else Lasker Schüler para «Hebräische Balladen» [“Baladas Heraicas"] de 1913.10 
Em 2015, no XXI ELS-Forum, que decorreu de 20 a 22 de Novembro, comemorando os vinte e cinco anos da Sociedade ELS, com o tema - Damit Menschen nicht Flüchtlinge werden! [Para que as pessoas não se tornem refugiados], alerta para o facto de os Alemães já terem sido eles próprios refugiados. Foi o caso de Else Lasker-Schüler, bem como o de alguns dos seus alter-egos ficcionais, cujo mote é: "Ein einzelner Mensch ist oft ein ganzes Volk"11 [Uma só pessoa é muitas vezes todo um povo"]. Jussuf, também ele, foi um refugiado, morto há setenta anos em Jerusalém. A própria Else diz:

Ich bin in Theben (Ägypten) geboren, wenn ich auch in Elberfeld zur Welt kam im Rheinland. Ich ging bis 11 Jahre zur Schule, wurde Robinson, lebte fünf Jahre im Morgenlande, und seitdem vegetiere ich. ${ }^{12}$

[Nasci em Tebas (Egipto), se bem que tenha vindo ao mundo em Elberfeld, na Renânia. Andei na escola até aos 11 anos, tornei-me Robinson, vivi cinco anos no Oriente e, desde então, vegeto.]

A contracena entre o interior e o exterior, que sempre se deu no teatro de operações dos seres, é muito visível na obra de Lasker-Schüler. A sua escrita denota uma lucidez profunda face às toadas do seu tempo e dos espaços por onde andou, só raramente sentindo que à sua volta houvesse quem partilhasse dos contornos da sua existência. João Barrento avalia esta característica de transmigração exterior e interior na autora, assim:

[...] A errância foi aliás aquilo que marcou, desde os anos de boémia berlinense, antes da Primeira Guerra, até aos últimos anos de vida na Palestina, a vida desta poète maudite que falava com os anjos em língua de criança, uma língua mágica que partilhava com outro poeta da imagem e da consciência do trágico, o austríaco Georg Trakl [...]. É certo que o azul de morte de Trakl não é o azul real e luminoso dos poemas e dos desenhos de Lasker-Schüler (nem também o azul da fantasia libertadora dos cavalos de Franz Marc, [...]. Mas ambos são figuras trágicas num tempo que já era o do abandono de Deus e o da perda de todas as ilusões humanas. Por isso, a poesia dos dois [...], e apesar dos seus muitos momentos de jubilo espiritual e erótico - pode e deve ser lida como uma única e grande elegia. (Barrento 2002: 15-16)

Extra-vagante, Lasker-Schüler, ora se vestia de homem ora de mulher e é assim que 
Gottfried Benn fala dela e da primeira vez que a viu:

Es war 1912, als ich sie kennenlernte. Es waren die Jahre des Sturms und der Aktion, deren Erscheinen wir jeden Monat mit Ungeduld erwarteten [...] Sie war klein, damals knabenhaft schlank, [...] große rabenschwarze bewegliche Augen mit einem ausweichenden unerklärlichen Blick. Man konnte weder damals noch später mit ihr über die Straße gehen, ohne da $\beta$ alle Welt stillstand und ihr nachsah: extravagante weite Rocke oder Hosen ... Und dies war die größte Lyrikerin, die Deutschland je hatte. (Benn 1959: 537)

[Corria 1912, quando a conheci. Eram os anos de Der Sturm e de Die Aktion, cujo aparecimento todos os meses aguardávamos com impaciência ... Ela era pequenina, então esguia como um rapaz, tinha olhos grandes, vivos, negros como os de um corvo, com um olhar fugidio e inexplicável. Nem naquela altura nem mais tarde era possível ir com ela na rua sem que toda a gente ficasse parada a mirá-la: saias ou calças largas, extravagantes... E era esta a maior poeta que a Alemanha jamais teve].

Desta dinâmica de surpresa e suspense, que as fanzines expressionistas geravam, deve realçar-se aqui o facto de Lasker-Schüler manter laços de amizade muito fortes com Franz Marc - co-fundador do almanaque de Munique Der Blaue Reiter - com quem se correspondia através de postais poéticos, desenhados e pintados, quer por ela quer por ele, e sentia uma grande atracção pelo conceito kandinskiano de Necessidade Interior de Der Blaue Reiter..$^{13}$ A correspondência entre Else e Marc (muitas vezes também Maria Marc), que tem início em 1912 e se prolonga até 1919, faz-se através de postais de dupla face, prosa poética de um lado e pintura do outro. ${ }^{14}$ Manifesta uma grande afinidade de sensibilidade artística e processa-se no foro do jogo efabulatório pró-infantil. Inventam-se personagens fictícias que, através do distanciamento do real, envergam identidades de compatibilidade funcional que instiga a criação. Else Lasker-Schüler quase sempre assina os postais como Prinz Jussuf von Theben - personagem que ascende, mais tarde, a Kaiser Malik, o protagonista do seu romance ilustrado de 1919 sobre amor e guerra, também dedicado a Franz Marc: "Dem blauen Reiter in Ewigkeit" ["Ao cavaleiro Azul na Eternidade"].

As figurações de identidade masculinas, adoptadas por ELS na sua correspondência 
com Franz Marc, mostram que é mais imediata a libertação jocosa entre duas pessoas do mesmo sexo, mas não impedem os autores dos postais de se centrarem em temas como a maternidade e, simultaneamente, procederem a uma encenação intertextual com as artes plásticas. Jussuf faz-se acompanhar de outras personagens, como Abigail nesta tessitura de comunicação caleidoscópica em que texto e imagem se complementam. Os autores, através das personagens que encarnam, projectam-se no mágico mundo epistolar multidiscursivo: "Lieber Prinz, dies ist die Mutterstute der blauen Pferde, aus dem Gestüt des Prinz von Theben“ ["Caro Príncipe, esta é a mãe égua dos potros azuis, da coudelaria do Príncipe de Tebas"], escreve Marc no verso de uma pintura sua (Marquardt/Rölleke, Hg. 1998: 60).

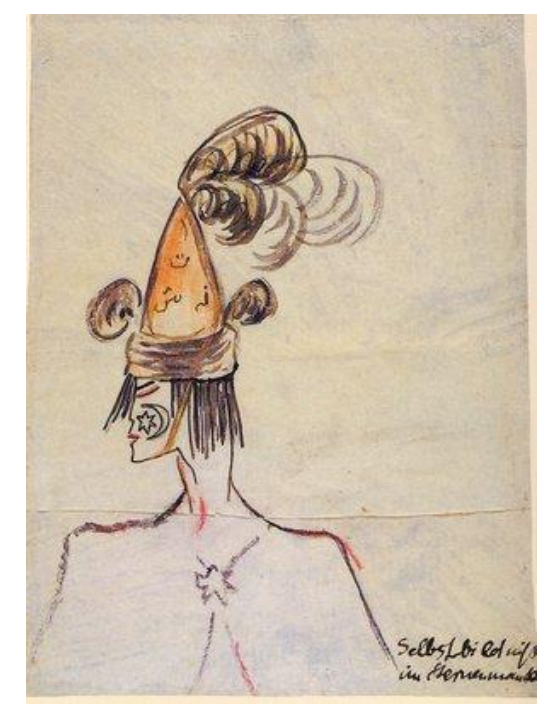

Else Lasker-Schüler, Selbstbildnis im Sternenmantel [Auto-Retrato em Casaco de Estrelas]

Os textos de Franz Marc nos postais a Els articulam-se com o disfarce exterior para demonstrarem a identificação interior. É como se Marc aprendesse com Else a ultrapassarse a si próprio, auto-estilizando-se naquele mundo inventado. 0 processo de abstracção materializa-se, assim, na escrita, através da valência icónica. Else Lasker-Schüler e Franz Marc desencadeiam um acto literário-pictórico em que o idioma da vontade própria dá visibilidade a uma encenação com pendor arábico.

Nos postais (manuscritos, claro) a corporalidade da escrita emerge e Prinz Jussuf 
dirige-se a Franz Marc, por exemplo, com um "Mein lieber, wundervoller blauer Reiter" ["meu querido, maravilhoso cavaleiro azul"]. 0 conteúdo escrito dos postais versa uma toada idêntica à do conteúdo utópico- pictórico, sem, contudo deixar de focar assuntos e estados de espírito reais.

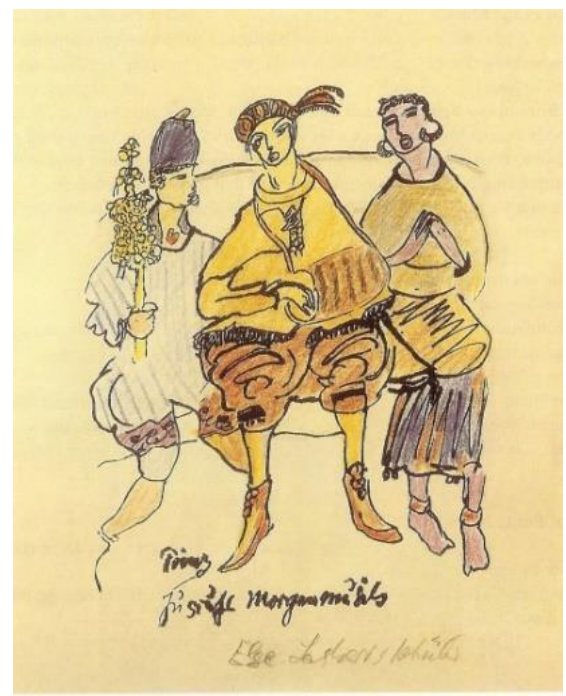

Else Lasker-Schüler, Prinz Jussufs Morgenmusik, postal a F. Marc, em 9 de Novembro de 1912

Neste postal, chamado "Prinz Jussufs Morgenmusik" [“A música da manhã do Príncipe Jussuf'], o desenho E. Lasker-Schüler estabelece uma analogia entre a música e a poesia. 0 príncipe toca para os amigos. Por seu lado, o texto anuncia que o príncipe levará consigo muitas poesias. E, dando conta de coisas que realmente se estavam a passar na realidade, diz assim:

Wertester Maler,

Wenn ich nach München komme, (ich bin Jussuf der Prinz von Theben) soll ich Franz Marc besuchen? Die blauen Reiter schenken Sie mir dann eine Stunde und ich bringe Ihnen bunte Steine ${ }^{15}$ mit. Ich habe viele Gedichte gedichtet, auch die Versöhnung - warum haben Sie die Versöhnung gezeichnet sind Sie auch so schmerzlich verloren wie ich, da $\beta$ ich keinen Weg mehr habe nur Schluchten. (Marquardt/Rölleke, Hg., 1998: 28) 
[Valoroso Pintor,

Quando eu for a Munique, (sou o Príncipe Jussuf de Tebas) devo visitar o Franz Marc? Os cavaleiros azuis concedem-me uma hora e eu levo-lhes pedras multicolores. Poetei muitos poemas, a Reconciliação também - porque ilustrou a Reconciliação - também está tão dolorosamente perdido quanto eu, que não tenho outra saída senão soluçar. (sic)]

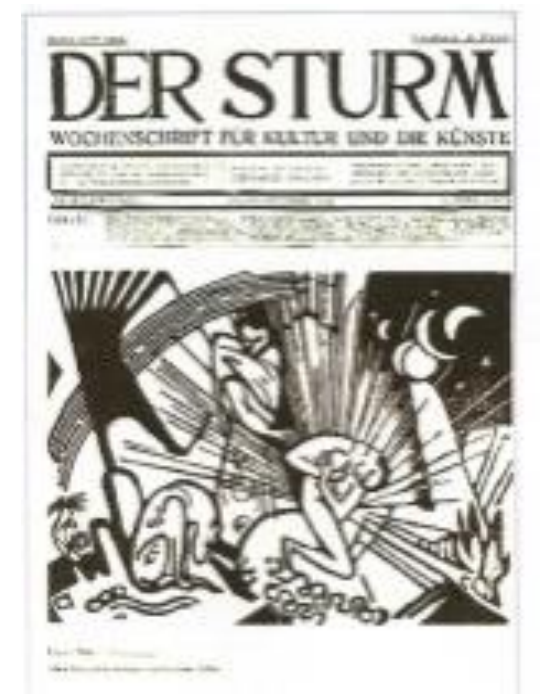

Capa do no 23 de Der Sturm, 1912, com a ilustração de Franz Marc do poema «Versöhnung» (1910) de LaskerSchüler.

A presença articulada do texto e da imagem surge, de novo, em Briefen nach Norwegen [Cartas para a Noruega], dirigidas, desta vez, a Herwarth Walden ${ }^{16}$, prestes a deixar de ser seu marido, e assinadas por Prinz Jussuf, publicadas em Der Sturm, como semi-fictícias, entre 1911 e 1912. Esta série é depois intitulada pela autora de «Briefe und Bilder» [“Cartas e Quadros"], que passam também a sair em Die Aktion, Der Brenner e Die Neue Jugend. Em 1913, surgem em livro sob o título Mein Herz - Ein Liebesroman mit Bildern und wirklich lebenden Menschen [O Meu Coração - Um Romance de Amor com quadros e pessoas realmente vivas]. Estas cartas combinam o tom efabulatório com um acentuado pendor satírico no relato de situações do dia-a-dia artístico berlinense.

Um outro alter-ego de Else é a princesa Tino. 0 livro Die Nächte der Tino von Bagdad [As Noites de Tino de Bagdad] (1907) é publicado por Paul Cassier em 1919. Trata-se de 
uma série de contos, com grafismo gótico, escritos numa fase de separação do seu primeiro marido, o médico Berthold Lasker, pai do seu filho Paul.

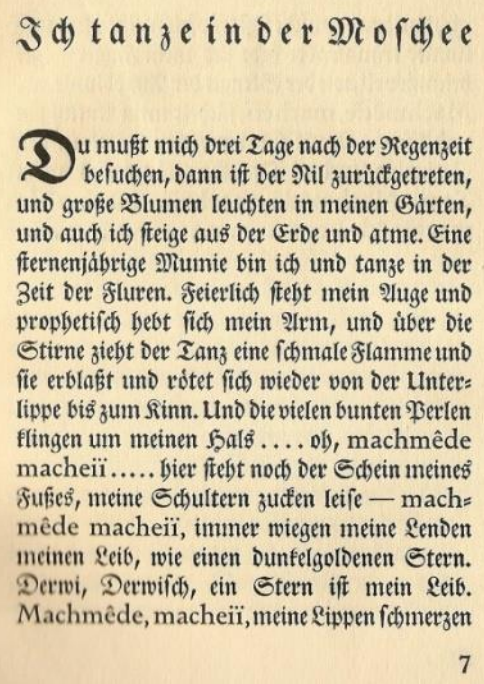

"Ich Tanze in der Moschee“, E. Lasker-Schüler (1907), na 1a edição de Die Nächte der Tino von Bagdad, 1919.

Os contos das Noites relatam um sonho passado no oriente, em que Lasker-Schüler faz emergir pequenos laivos da língua árabe que repete ritmicamente. Vejamos um excerto de "Ich tanze in der Moschee" ["Danço na Mesquita”]:

... die vielen bunten Perlen klingen um meinen Hals....oh, machmêde macheiï.... hier steht noch der Schein meines Fußes, meine Schultern zucken leise - machmêde macheiï, immer wiegen meine Lenden meinen Leib, wie einen dunkelgoldenen Stern. Derwi, Derwish, ein Stern ist mein Leib. Machmêde macheiï, meine Lippen schmerzen nicht mehr...(Lasker-Schüler 1919: 7)

[...as muitas pérolas coloridas tinem à volta do meu pescoço.... Oh, machmêde macheiï...... ainda está aqui o brilho do meu pé, um frémito ligeiro percorre-me os ombros - machmêde macheiï, as coxas embalam-me o corpo, como a uma estrela de negro ouro. Derwi, Derwish, o meu corpo é uma estrela. Machmêde macheiï, os lábios já me não doem...]

A princesa Tino fala como se fala nos sonhos. 0 sentido do texto só o encontramos na projecção visual que dele fizermos. Para além de se ver, este texto ouve-se, leva a intuir 
alguma viabilidade na adaptação do espaço e do tempo ao ritmo e à visibilidade do texto. Esta estratégia discursiva é usada diegeticamente, quando a personagem da princesa interage com os heróis dos contos enquanto bailarina. Por exemplo, no conto Der Großmogul von Philippopel, em que Tino transmite as decisões do Grande Mugol, deliberadamente mal traduzidas, ao seu ministro. Usa uma língua que não é nem a oficial nem a dela, mas sim a linguagem do amor diplomático, que consegue distorcer a autoridade e reconverter a postura do poder: assim, acaba-se com a guerra e traz-se prosperidade ao país, acaba-se com a pena de morte, com os impostos e até se constroem palácios para quem precisa de tecto. No processo de descodificação de uma língua para outra, Tino expressa o que lhe dita a sua justiça interior.

Do fórum artístico, em que o Expressionismo emergia, Lasker-Schüler apenas auferiu das suas escolhas sempre tangíveis ao seu domínio ficcional, marcado por uma rica e trabalhada interioridade que a salvassem duma circunstancialidade abrupta. A perda e o amor são os seus motes desencadeadores de uma transfusão do interior para um outro interior, pleno de detalhes metonímicos, reveladores da tangibilidade entre o real e o que dele se pode fazer.

A escrita de Else Lasker-Schüler é abstraccionista para se projectar em representação no interior do leitor. Os contos ortónimos de 1910 como Tigerin, Affe und Kuckuck [A Tigreza, o Macaco e o Cuco], Im Neopathetischen Kabarett [No Cabaret Neopatético], entre outros, são disso belíssimos exemplos. Nestes contos, Else LaskerSchüler sai da encenação de si própria perante os outros, como faz nas cartas e nos postais e foca-se na realidade circundante, como os artistas e ocorrências nas suas vidas. São textos em que a autora está muito mais relacionada consigo própria e com o leitor. 0 leitor é interpelado frequentemente, quer por elementos textuais, quer por detalhes de plasticidade que permitem a projecção de imagens na mente. Este processo possibilita a partilha de uma sensibilidade de alguém que realmente existe, quando olha de dentro para fora de uma forma filtrada.

No conto Künstler [Artistas] deparamo-nos com uma criatura imaginária Herr Kuckuck ${ }^{17}$, que se sentava sempre no beiral da janela da narradora e debicava todas as suas 
palavras tristes. O seu marido nunca se dava conta da presença de Kuckuck. A narradora autodiegética tinha acesso a diferentes realidades das do seu marido e Kuckuck era delas um organismo regulador:

(...) Ich rieche zu gern Ananas - ich glaube, wenn ich mir täglich eine Ananas kaufen könnte, ich wurde die hervorragendste Dichterin sein. Alles hängt von Kuckucks Budget ab. Mein Mann der wünscht sich gar nichts mehr, er denkt morgens schon heimlich an seine Zigarette, die er im Bett rauchen wird. (...) (Lasker-Schüler 1998b: 160-1)

[(...) Gosto de cheirar ananás - acho que se pudesse comprar um ananás todos os dias, me tornaria na poeta mais requisitada. Tudo depende do budget do Kuckuck. 0 meu marido, ... praticamente não queria mais nada, senão, pensar, logo pela manhã, no cigarro que iria fumar na cama. (...)]

Neste caricato ambiente de incomunicabilidade entre marido e mulher, surge um imponderável: falta a luz, o cigarro cai, ele, aflito, chama por ela, consegue apanhar o cinzeiro do chão e lá pôr o cigarro e, faz-lhe, então, uma festa na cara com a mão a cheirar a ananás [„Ananashand”]. 0 cómico advém do absurdo, mas Kuckuck aparece, deixa-se ser visto pelo homem e devolve o sentido à situação, ou pelo menos um sentido, de forma retórica: “»Wer bist du!« Ruft mein Mann. »Ich bin der Schatten Ihrer Frau und habe Theologie studiert«" [“»uem és tu?!« Grita o meu marido. »Eu sou a sombra da sua mulher e estudei Teologia«"]. Os vocábulos Ananas e Kuckuck, pela sua sonoridade, visibilidade ortográfica e jogo mental, exercem no leitor uma cinestesia que dispensa a verbalização, por fazerem sentir o que se quer dizer. Acresce a esta conjuntura em que a palavra filtra os sentidos, o facto de Kuckuck ter estudado Teologia, o que nos transporta para uma espécie de combate de pensamento: lidaremos com um Godot ou com um Deus?

Kuckuck reaparece no conto-fábula Tigerin, Affe und Kuckuck [A Tigreza, o Macaco e o Cuco] para revelar aos homens que os animais não são fadados para a actividade circense. Essa é uma aptência humana, que Darwin, segundo o conto, não enunciou. Kuckuck, o amigo misterioso que traz a narradora à razão do inefavelmente mágico, ou seja, o mais intimamente ligado ao que nos é circundante - contra o que muitas vezes nada podemos e aquilo que é transversal a todos os homens e que só a abstracção consegue mudar. A 
forma das coisas passa pela captação de novas significações e da sua transmissão aos outros, que a espiritualização na arte expressionista veiculou.

O conto Am Kurfürstendamm - Was mich im vorigen Winter traurig machte... [Em Kurfürstendamm - O que me pôs triste no Inverno passado...] fala de forma e abstração. Else Lasker-Schüler aqui faz confluir a distanciação e a abstracção na partição ponderada entre sombras e luz a que Goethe chama Claridade18. No conto a narradora observa a bela e engalanada alameda de Kurfürstendamm, com toda a animação veraneante da promenade berlinense do início do século XX. Contudo o seu olhar fixa-se nos cavalos que passeiam as raparigas:

Wenn die lieblichen Reiterinnen im Sommer auf ihren verwöhnten Schimmeln durch die Allee des Kurfürstendamms reiten, wird der Geranium zu ihren Seiten rot wie die vergossenen Blutstropfen der armen Pferde blühen. Sie hatten allen traurige Augen und ließen die Köpfe hängen. (Lasker-Schüler 1998b: 172)

[Quando, no Verão, as adoráveis cavaleiras montam os seus acarinhados cavalos brancos, as magnólias, por seu lado, florescem vermelhas como as gotas esquecidas de sangue dos pobres cavalos. Todos tinham os olhos tristes e deixavam cair a cabeça.]

Este é um quadro expressionista, escrito por Else Lasker-Schüler, facilmente tratável pelos Estudos Pós-Humanos. 0 traço que dá forma às figuras humanas é forte e satírico e contracena com o vermelho intenso das gotas imaginárias do esquecido sangue dos cavalos. Os cavalos são a essência do quadro: todos têm olhos tristes e cabeça caída. Da realidade exterior, só a narradora tal vê. A sua postura conceptual mexe, uma vez mais, com o processo de significação e de percepção. E é, de novo, a dimensão da interioridade que transpõe um novo código para a escrita, em que a mediação da ressonância interior é aqui feita pelo pensamento, que empresta a voz à anulação das diferenças exteriores e releva a identidade interna.

O conto Im Neopathetischen Kabarett [No Cabaré Neopatético], começa assim: "Tausend und Einer. Ich habe mich nicht verzählt" [“Mil e Um. Não me contei a mim”], o que enceta um relato cómico-absurdista de um lugar pululante de figuras públicas do meio 
artístico expressionista. 0 efeito de distanciação brechtiano está particularmente presente neste texto. Decorria um recital de poesia, mas o filtro do olhar da narradora via apenas poses, adereços e trejeitos indiferentes ao que de poético se poderia estar a passar. De novo a palavra e a imagem são convertidos em correlatos. Neste conto, como é recorrente na escrita de Else Lasker-Schüler, o que aparece celebra o que não aparece. A narradora nem aparece, nem vê o que os restantes ocupantes do local vêem. 0 que é relevado é a fixação do olhar em Zobeide, a sua bailarina, e o alhear de todo o resto. A perspectiva altera-se a partir do interior da narradora e a forma das coisas distorce:

(...) wenn Zobeide, meine Tänzerin, ein Portemonnaie bei sich hätte, würde ich doch zu der Menschhitze kein Glas Limonade trinken. Ich höre, wie ein Vortragender mit triumphierendem Gesicht Stephan Georges Dichtungen als Ruhe punkt bezeichnet. (...)

Gern hätte ich die Rede von Kurt Hiller, dem Präsident des Neopathetischen Kabaretts, gehört. Zobeide, meine Tänzerin, will noch nicht nach Hause kommen. (Lasker-Schüler 1998b: 192-3)

[Se a Zobeide, a minha bailarina, tivesse com ela um porta-moedas, eu não iria beber sequer um copo de limonada ao empolgamento das pessoas. Apercebo-me de como um diseur de semblante triunfante assinala o ponto de ordem com a poesia de Stefan George. (...) Teria tido todo o gosto em ouvir o discurso Kurt Hiller ao Presidente do Cabaret Neopatético. Zobeide, a minha bailarina, ainda não quer vir para casa.]

A prioridade matricial dos olhos é estabelecer a ligação entre interior e exterior. Else Lasker-Schüler reúne um tipo de plateias distinto, porque lhes é solicitado um esforço cognitivo de confrontação do exterior com o interior que induz a outras condições epistémicas. A sua modalidade de escrita nos contos de 1910 é analógica, descontínua e sincrética. É uma escrita geradora de imagem e dela oriunda. Ao transpor a informação que um sentido recebe para os outros sentidos, produz novas formas de recepção e de reacção. O estilo literário-plástico de Lasker-Schüler serve de plataforma para toda uma concepção poética interactiva. E é na poesia que dá conta da sensação de viver num mundo cada vez mais caótico, ameaçador e instável, do ponto de vista pessoal e nacional. Em "Heimweh" [“Saudade"], escreve: "Ich kann die Sprache / Dieses kühlen Landes nicht, / Und seinen 
Schritt nicht gehen”. [Não consigo falar a língua / Deste país frio, / Nem seguir-lhe o passo."]".

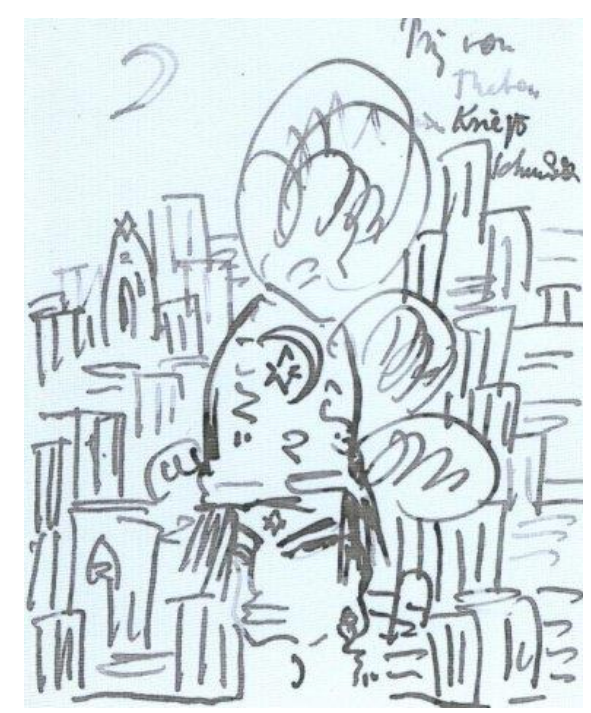

Else Lasker-Schüler, Prinz von Theben im Kriegsschmuck [O Príncipe de Tebas com adorno de guerra]

Mas é justamente na instabilidade e na fragilidade da vida berlinense que ela encontra uma intensa afinidade pessoal e espiritual que converte numa poderosa metáfora para a arte. A omnipresença é um estado de eleição no seu universo preferido, como demonstra em Gebet - que começa com o notável verso "Ich suche allerlanden eine Stadt", ["Em todas as terras procuro uma cidade"] e termina com o verso "Und sich ein neuer Erdball um mich schließt” [“E uma nova Terra me vai cercar”.].19 


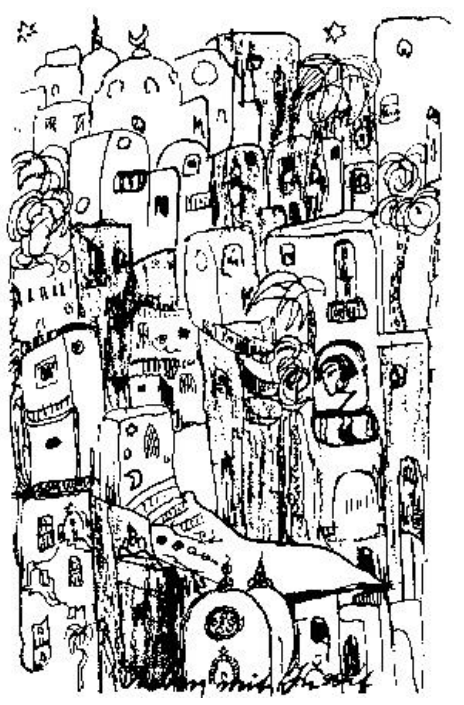

Else Lasker-Schüler, Theben mit Jussuf

Em 1910, já bem conhecida como poeta em Berlim - publicou "Leise Sagen” [“Em Voz Baixa"] na revista Der Sturm, editada por Herwarth Walden, ainda seu marido. É um poema que dá início a uma escrita revisitada, em que podemos ler: "Im Spiegel der Bäche / Finde ich mein Bild nicht mehr." [0 espelho das correntes / Já não me mostra a minha imagem"]. A forma poética schüleriana responde a esta condição com o desmonte da organicidade do mundo material, condicionante e causador de perplexidade e dor, para o transformar em conteúdos de verdade imaterial. À montagem dessa imaterialidade estética na poesia de Lasker-Schüler subjaz uma simbólica monumental, feita de estrelas, anjos, luz, cores, luas, sois, noite, sons, infância, divino. Observemos como ela projecta essa montagem num dos seus mais conhecidos poemas:

Versöhnung

Es wird ein großer Stern in meinen Schoß fallen ... Wir wollen wachen die Nacht,

In den Sprachen beten,

Die wie Harfen eingeschnitten sind.

Wir wollen uns versöhnen die Nacht -

So viel Gott strömt über.
Reconciliação

Há-de uma grande estrela cair no meu colo... A noite será de vigília,

E rezaremos em línguas Entalhadas como harpas.

Será noite de reconciliação -

Há tanto Deus a derramar-se em nós. 
Kinder sind unsere Herzen,

Die möchten ruhen müdesüß.

Und unsere Lippen wollen sich küssen,

Was zagst du?

Grenzt nicht mein Herz an deins -

Immer färbt dein Blut meine Wangen rot.

Wir wollen uns versöhnen die Nacht, Wenn wir uns herzen, sterben wir nicht.

Es wird ein großer Stern in meinen Schoß fallen ...
Crianças são os nossos corações,

Anseiam pela paz, doces-cansados.

E nossos lábios desejam beijar-se -

Por que hesitas?

Não faz meu coração fronteira com o teu?

0 teu sangue não pára de dar cor às minhas faces.

Será noite de reconciliação,

Se nos dermos, a morte não virá.

Há-de uma grande estrela cair no meu colo...

É radical nas metáforas que usa. O seu universo poético apela aos sentidos, muito mais do que ao sentido. "Uma palavra tem de beijar a outra". A poesia em que uma palavra beija a outra fala uma língua que remete para um estado de indiferenciação em que tudo se encadeia, (...). Em "Versöhnung"20, poema escrito para o dia de Yom Kippur, é notório que Lasker-Schüler acreditava que, tanto os deuses como as artes têm a mesma raiz. A imagem de uma estrela que cai no colo é desde logo uma sonante metáfora para uma concepção do universo que está na linha da tradição hermética, segundo a qual o comportamento do indivíduo e do universo estão em correspondência micro e macro-cósmica. A metáfora da estrela está quase sempre patente em tudo que Else Lasker-Schüler escreve ou desenha, não só revela a sua identidade judia, como é uma cifra indissociável do Ser do Amor, do segredo da criação cósmica, do nascimento, da lei da vida, da proximidade de Deus. A estrela que cai no colo desencadeia toda uma configuração espiritual, em que o figurativo está ao serviço da abstracção. Com uma estrela ao colo, ela tem a noite e a inorganicidade cósmica por companhia. Inventa um novo saber, em que há uma língua-franca: aquela em que todas as línguas rezam, tecendo um alter-mundo parecido com o das "harpas".

A estrutura deste poema é muito singular: sete estrofes com dois versos e uma com um, sendo esta última igual à primeira, o que nos leva a visualizar um ciclo que se fecha para dar lugar a outro, como as reticências indicam. Não há rima, contudo há um jogo que se processa por associação semântica, entre as palavras que fecham os versos, que provoca no leitor/ouvinte uma série de sensações cristalizadoras de sentido, como fallen/Nacht [cair/noite], beten/sind [a rezar/estamos], Nacht/über [noite/em cima], Herzen/müdesüß 
[corações/doces-cansados]. Estas primeiras quatro estrofes imprimem ao poema um ambiente de simbiose universal, em que há um "nós" que reza uno.

O segundo quadro ambiental do poema é vermelho e apela a um "tu" hesitante, mas cujos lábios e coração são espiritualmente tangíveis aos do "eu”. "Wir wollen" [queremos] preside aos três fragmentos percepcionais do texto. A intencionalidade é a de reconciliação e regressa no terceiro momento, constituído pela sétima e oitava estrofes. A métrica, sendo irregular, vai ao encontro da diversidade das três toadas de circunstância do poema, balizadas por "Es wird ein großer Stern in meinen Schoß fallen" ["Há-de uma grande estrela cair no meu colo"]. Para além disso, a métrica do poema produz uma mancha gráfica em semi-círculo concêntrico, que, por um lado sugere o globo terrestre em tangibilidade com o cosmos e, por outro, produz uma vibração visual centrípeta, que aponta para os "corações", palavra central desse semi-círculo: "Herzen".

Em «Ein alter Tibetteppich», Else Lasker-Schüler retoma o efabulamento onírico: a alma de alguém vive na dela e voa num tapete do Tibete, para entrar na dimensão da luz, onde as cores se apaixonam e as estrelas dançam. 0 rumo é o abraço adolescente dos povos.

\section{Ein alter Tibetteppich}

Deine Seele, die die meine liebet, Ist verwirkt mit ihr im Teppichtibet.

Strahl in Strahl, verliebte Farben,

Sterne, die sich himmellang umwarben.

Unsere Füße ruhen auf der Kostbarkeit, Maschentausenabertausendweit.

Süßer Lamasohn auf Moschuspflanzenthron, Wie lange küßt dein Mund den meinen wohl

Und Wang die Wange buntgeknüpfte Zeiten schon?

\section{Um velho tapete do Tibete}

A tua alma e a minha amam-se e encontram-se Entretecidas num tapete tibetano - tornaram-se

Feixes de luz, cores de paixão, e agora São estrelas, namorando pelos céus fora.

Nossos pés repousam nessa jóia querida De-malhas-mil-de-mil-malhas-tecida.

Doce filho do Lama, em trono almiscarado, Desde quando a tua boca beija a minha E as cores dos tempos tecem nosso abraço?21

Dá-se um plano picado para uma nova personagem - imagem arquétipo do amor sem tempo nem espaço ("buntgeknüpfte Zeiten"), formalmente acarinhado pela aliteração e pelo jogo de palavras, que aponta para o que havia dito Franz Marc em 1914, no texto Im Fegefeuer des Krieges [No Purgatório da Guerra]: Der kommende Typ des Europäers wird 
der deutsche Typ sein; aber zuvor mu $\beta$ der Deutsche ein guter Europäer werden [Os Europeus do futuro serão como os Alemães, mas então, os Alemães terão que se tornar bons Europeus] ${ }^{22}$.

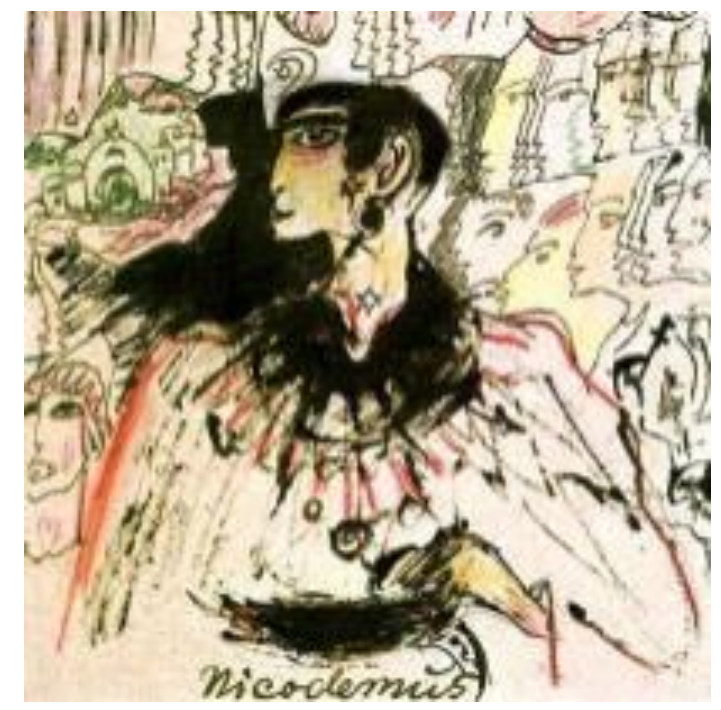

Else Lasker-Schüler, Nicodemus, 1923

A condição sub-humana a que a matriz vigente obriga em troco de segurança despoleta a necessidade de entender como percepcionar idealmente o espaço e o tempo em que nos movemos. Em 2002, Gonçalo Vilas-Boas adverte para a precariedade da integridade individual que se avistava: "Se encontramos muitas utopias positivas até ao século XX, notamos também que a partir da primeira guerra mundial começam a dominar as distopias. As razões para tal mudança são essencialmente históricas. Mas em qualquer dos casos estamos perante sociedades altamente regulamentadas onde o lugar do Eu individual não está garantido" (Vilas-Boas 2002: 95-6). 0 percurso discursivo de Lasker-Schüler faz-se pela via da abstracção, obtida através de um processo de filtragem interior da mundividência. A construção de alter-egos era, no caso de Lasker-Schüler, uma forma de transgredir os limites impostos por um exterior que ela transfigurava numa necessidade de repensar categorias estéticas com uma base de novas construções físicas e metafísicas. Uma espécie de innernet, labiríntica e en garde para ser libertadora. 


\section{Bibliografia}

Anz, Thomas \& Stark, Michael, Hg. (1982), Expressionismus - Manifeste und Dokumente zur deutschen Literatur 1910-1920, Stuttgart, J.B. Metzlersche Verlagsbuchhandlung \& Carl Ernst Poeschel Verlag GmbH.

Barrento, João (1989), A Poesia do Expressionismo Alemão, Lisboa, Editorial Presença.

(2002), Baladas Hebraicas, edição bilingue, tradução / apresentação João Barrento, Lisboa, Assírio e Alvim.

Bauschinger, Sigrid (1980), Else Lasker-Schüler: Ihr Werk und ihre Zeit, Heidelberg, Stiehm.

Benn, Gottfried (1959), „Rede auf Else Lasker-Schüler“, Gesammelte Werke, Band I, Wiesbaden, Klett-Cotta.

Cesariny, Mário (1985), As Mãos na Água, A Cabeça no Mar, Lisboa, Assírio e Alvim.

Lasker-Schüler, Else (1919), Die Nächte der Tino von Bagdad, Berlin, Paul Cassier.

-- (1996), Der Prinz von Theben, Frankfurt a.M.: Suhrkamp Verlag [1914].

-- (1998a), Gesammelte Werke in drei Bänden - Gedichte, Hg. Friedhelm Kemp, Band 1, Frankfurt am Main: Suhrkamp Verlag.

-- (1998b), Gesammelte Werke in drei Bänden - Prosa und Schauspiele, Hg. Friedhelm Kemp, Band 2, Frankfurt am Main, Suhrkamp Verlag.

-- (1998c), Gesammelte Werke in drei Bänden - Verse und Prosa aus dem Nachlaß, Hg. Friedhelm Kemp, Band 2, Frankfurt am Main, Suhrkamp Verlag.

-- (2003), Mein Herz - ein Liebesroman mit Bildern und wirklich lebenden Menschen, Frankfurt a.M., Jüdischer Verlag im Suhrkamp Verlag [1912].

Marquardt, Ulrike \& Rölleke, Heinz, Hg. (1998), Else Lasker-Schüler / Franz Marc - Mein lieber, wundervoller blauer Reiter. Privat Briefwechsel, Düsseldorf, Zürich, Artemis und Winkler. 
McLuhan, Marshall (2000), The Gutenberg Galaxy - the making of typographic man, Toronto, Buffalo, London, University of Toronto Press [1962].

Miller, Cristanne (1999), “Reading the Politics of Else Lasker-Schüler's 1914 Hebrew Ballads", in Modernism/modernity, Vol. 6, no. 2, April, pp.135-159.

Pintus, Kurt (1959), Menscheitsdämmerung: ein Dokument des Expressionismus. Mit Biographien und Bibliographien, Hamburg, Rowohlt [1922].

Stifter, Adalbert (1981), Bunte Steine, disponível em http://gutenberg.spiegel.de/buch/bunte-steine-197/1

Vilas-Boas, Gonçalo (2002), “Utopias, Distopias e Heterotopias na Literatura de Expressão Alemã", Utopias - Cadernos de Literatura Comparada 6/7, Instituto de Literatura Comparada Margarida Losa, FLUP / FCT, Porto, Granito Editores e Livreiros, 95-118. 
Manuela Veloso é Doutorada em Literatura Comparada (2008) e Professora Adjunta no ISCAP/Instituto Politécnico do Porto, lecionando Tradução Técnica e Literária (Alemão/Inglês - Português). É membro do ILCML desde 2007. Com particular incisão nas questões da auto-tradução e da dupla-vocação na escrita e na pintura, bem como da confluência da teoria e da criação artísticas num mesmo autor, tem publicado diversos artigos em revistas nacionais e estrangeiras, abordando a intermedialidade da Identidade no Modernismo Europeu, embrionário de novas possibilidades percetuais na exegese textual e socio-ambiental, de um ponto de vista cinestésico e transindividual, em interface com uma semiótica global.

\section{NOTAS}

1 Este artigo insere-se na investigação desenvolvida no ILCML, no âmbito do Programa Estratégico UID/ELT/00500/2013.

2 Else Lasker-Schüler, Der Schlangenanbeter auf dem Marktplatz in Theben [A Encantadora de Serpentes em Tebas]. Tradução minha, o que farei daqui em diante, quando não houver uma tradução publicada.

${ }^{3}$ Citado a partir da antologia de ensaios de Mário Césariny, As Mão na Água, a Cabeça no Mar (1985: 114).

4 Do primeiro livro Styx, Berlim, 1912. Tradução de João Barrento (2002: 13).

5 Título de um artigo no Le Monde (09. Junho.1989) de Bott François sobre Else Laskar-Schüler. Neste artigo é citado J. M. Palmier ( $v d$. www.alapage.com).

${ }^{6}$ A Else-Lasker-Schüler-Gesellschaft publicou um catálogo da exposição, com a colaboração dos autores Sigrid Bauschinger, Itta Shedletzky, Ricarda Dick, Ulrike Marquardt, Roswitha Klaiber, Andrea Suppmann, Margarethe Jochimsen, Karl Jürgen Skrodzki, Markus Hallensleben und Rainer Stamm, autores que se têm vindo a debruçar 
sobre a obra de Lasker-Schüler no contexto do Modernismo europeu e no âmbito da sua ligação às revistas literário-artísticas que orbitraram em torno do Expressionismo.

7 Tradução de João Barrento (Barrento 1976: 191).

8 Entrevista de Yarden Katz a Noam Chomsky (Nov 1 2012, 2:22 PM ET 62), publicada com o título "Noam Chomsky on Where Artificial Intelligence Went Wrong". Disponível em http://www.theatlantic.com/technology/archive/2012/11/noam-chomsky-on-where-artificial-intelligencewent-wrong/261637/

${ }^{9}$ http://www.else-lasker-schueler-gesellschaft.de/

10 Traduzidas para Português por João Barrento (2002).

${ }^{11}$ Primeiro verso do poema inacabado „Ein einziger Mensch“, que começa assim: „Ein einziger Mensch ist oft ein ganzes Volk / Doch jeder eine Welt" [Um só individuo é tantas vezes todo um povo / Ainda que cada um um mundo] (Lasker-Schüler 1998c: 113).

${ }^{12}$ Curriculum de ELS para a antologia Menscheitsdämmerung (Pintus: 1959).

13 É neste almanaque do Expressionismo de Munique, que Kandinsky publica Der gelbe Klange. Eine Bühnenkomposition [O Som Amarelo, Uma Composição para Palco], com a partitura de Schönberg que integra a peça de 1 acto, dividida em 6 quadros. Há um dueto em combate de essências: uma criança de branco que representa a vida e um adulto de negro que representa a morte - a Natureza contracena com o Homem.)

${ }^{14}$ Os postais estão expostos na Staatliche Graphische Sammlung, em Munique, e na National Galerie, em Berlim. Encontram-se também compilados no livro Else Lasker-Schüler / Franz Marc-Mein lieber, wundervoller blauer Reiter. Privat Briefwechsel (Marquardt/Rölleke, Hg. 1998).

15 A referência a "bunte Steine", como observou Gonçalo Vilas-Boas numa conversa de orientação do meu doutoramento, remete para os contos Bunte Steine, publicados em 1853, de Adalbert Stifter (1805-1868), em que é marcante o tema Civilização versus Natureza, onde as cores têm um fortíssimo poder simbólico e as pedras habitam uma dimensão própria:

Eines Tages war in den Steinen eine besondere Hitze. Die Sonne hatte zwar den ganzen Tag nicht ausgeschienen, aber dennoch hatte sie den matten Schleier; der den ganzen Himmel bedeckte, soweit durchdrungen, da $\beta$ man ihr blasses Bild immer sehen konnte, da $\beta$ um alle Gegenstände des Steinlandes ein wesenloses Licht lag, dem kein Schatten beigegeben war (...). (Stifter, 1981: 283)

[Um dia, havia nas pedras um calor particular. 0 sol não tinha mesmo brilhado o dia todo. Mas, acabou por aparecer - o débil véu que cobria todo o céu, de tal forma compenetrado, que se podia ver incessantemente a sua 
imagem pálida e pousava em torno de todos os objectos do País das Pedras uma luz ilusória, à qual não se agregava qualquer sombra (...)]

${ }^{16}$ Herwarth Walden, músico, ensaísta e editor de Der Sturm, na sua teoria da "Wortkunst" [arte da palavra], "a percepção estética é o sentir", "a arte compreende o incompreensível mas não o conceptual”, "os efeitos estéticos não precisam de ter um sentido" (apud Barrento 1989: 83). É notório o entrosamento da Wortkunsttheorie com a produção escrita de Else Lasker-Schüler, uma vez que enaltece as potencialidades expressivas da obra de arte, como as relações rítmicas e harmónicas, o valor simbólico e plástico das cores e das formas, ou dos sons e das imagens. Walden fala também de Wortbild [imagem da palavra], ou seja o equivalente óptico e acústico da visão interior.

17 Traduzir-se-ia por Sr. Cuco, mas prefiro manter a sonoridade e visualidade ortográfica de Kuckuck.

${ }^{18}$ Sobre este tema goetheano, ver O Pensamento Morfológico de Goethe de Maria Filomena Molder (1995: 63).

${ }^{19}$ Este é um dos mais revisitados poemas de ELS, principalmente pela composição musical. Exemplo disso são as Symphonischen Kantate de Torsten Brandes, a partir de textos dela. "Gebet" tem um lugar privilegiado nesta abordagem, interpretada pela Brandenburger Symphoniker, cantado pelo Brandenburger Theaterchor, pela soprano solo Sabine Passow, com direcção do maestro Mathias Förster.

20 Um dos catorze poemas que integram a antologia de Kurt Pintus, Menschdämmerung (1920).

${ }^{21}$ Tradução gentilmente cedida por João Barrento (Janeiro, 2010).

${ }^{22}$ Publicado em Der Sturm em 1916, aquando da morte de Franz Marc em combate. Disponível em (DerSturm783)https://books.google.pt/books?id=Y1DgBQAAQBAJ\&pg=PT230\&dq=franz+marc+im+fegefeue $\underline{\mathrm{r}+\text { des+krieges+der+sturm }+1916}$ 